\title{
YAG Laser Spot Welding of PET and Metallic Materials
}

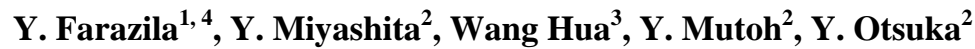 \\ 1 -Department of Mechanical Engineering, Nagaoka University of Technology, 940-2188 Nagaoka, Japan \\ 2- Department of System Safety, Nagaoka University of Technology, 940-2188 Nagaoka, Japan \\ 3- Department of Mechanical Engineering, Nagaoka University of Technology, 940-2188 Nagaoka, Japan \\ 4- Department of Engineering Design and Manufacture, University of Malaya, 50603 Kuala Lumpur, Malaysia \\ farazila@um.edu.my, miyayuki@mech.nagaokaut.ac.jp, mutoh@mech.nagaokaut.ac.jp
}

\begin{abstract}
Dissimilar materials joint has a great interest in industrial applications including automotives, aircrafts, medical, electronic industry, etc. Moreover, the combination of plastics and metals in the product would cater advantages in specific engineering application. In this study, direct joining using YAG laser spot welding for dissimilar materials joint between plastic and metallic materials has been investigated. Experimental result showed polyethylene terephthalate (PET) could be successfully joined to aluminum alloy (A5052), stainless steel (SUS 304) and copper (Cu). Shear tensile test was carried out to evaluate the joining strength. In the case of PET/Cu joint, the joining strength was almost constant regardless of heat input. However, the strength increased with increasing heat input for PET/A5052 and PET/SUS304 joints. Cross-sectional observation of the joined specimen showed no significant molten pool in the case of PET/Cu joint. On the other hand, an obvious weld pool was observed at the interface in metallic material side for PET/A5052 and PET/SUS304 joints. Differences of morphology at the interface would result from different material properties, such as reflectivity and absorptivity of laser, thermal conductivity, etc., of metallic materials used and might affect the joining strength.

DOI:10.2961/jlmn.2011.01.0015
\end{abstract}

Keywords: laser spot welding, YAG laser, dissimilar materials, PET, copper, stainless steel, aluminum alloy

\section{Introduction}

Small size and lightweight parts have been common and have strong demands in many industrial applications. In order to produce such products, combination of different materials may be required for the specific design. In the product design, metals usually have been selected since they have superior properties such as high ductility, high thermal conductivity, and high machinability. Meanwhile for plastics, they offer excellent corrosion resistance, insulation, and lightweight. Unfortunately the combination of metal and plastic in the product assembly makes them difficult to join together due to unlike material properties. Therefore adhesives and mechanical fastening have been usually applied to join dissimilar material application. However, these techniques have limitations in joining small size product with intricate shape. An appropriate joining technique should be proposed to improve the quality, production time and reliability of the dissimilar materials joint.

Laser process has been known as versatile tool for high precision manufacturing or material processing of small parts and geometries. Laser beam can be focused into very small size, which is useful for joining complex shape and micro parts. Moreover different parts even different materials can be joined as a non-contact process [1, 2]. Laser transmission welding (LTW) of plastics has been used in industrial application and offers many advantages compared to adhesives or screws. One of two parts must be transparent for the laser employed, while the other should has high absorption property [3]. Then laser irradiates and passes through the transparent material. The laser energy is converted into heat in the absorbing part and subsequently induces local melting in the joining region. The LTW was mainly used for joining a plastic and a plastic material, but for a plastic to a metal joint only few works have been reported [4-6]. Therefore, in this study, dissimilar materials joints between a plastic and metals were investigated. The joining strength was evaluated under tensile shear loading condition. The cross section of joined specimen was evaluated and thermal conductive analysis was carried out in order to understand the joint characteristics.

\section{Experimental procedure}

A plastic material used in this study was polyethylene terephthalate (PET) sheet of $0.5 \mathrm{~mm}$ thickness, while metal sheets used were copper (Cu) and aluminum alloy (A5052) of $1 \mathrm{~mm}$ thickness, and stainless steel (SUS304) of $2 \mathrm{~mm}$ thickness. All the test specimens were sheared into coupon size of $20 \mathrm{~mm} \times 10 \mathrm{~mm}$. The physical properties of the materials used are shown in Table 1. The plastic and metal surfaces were cleaned using ethyl alcohol and acetone, respectively, prior to welding.

The experiment was conducted in ambient air using pulsed Nd: YAG laser with fiber-optic beam delivery system. Lap joining experiments with various crest values in voltage for laser pumping and pulse duration were performed in this study. The lap joint arrangement for laser welding is shown in Fig. 1. In this experiment, the focal distance was adjusted 
into just focus position at the interface and the spot size was about $200 \mu \mathrm{m}$. The tensile shear test of joined specimen was carried out with the loading speed of $0.5 \mathrm{~mm} / \mathrm{min}$.

\section{Results and discussion}

\subsection{Weldability of the joints}

In this study, spot laser was applied to the combination between PET and metallic materials in order to achieve direct joining. The welding conditions for PET/A5052, PET/SUS304 and PET/Cu joints are shown in Table 2. The symbol " $\mathrm{x}$ " in the table represents the conditions for no formation of a weld. The values in the table indicate heat input (input energy for one pulse, $\mathrm{J} / \mathrm{p}$ ) of welding condition. From the table, it was found that PET/SUS304 joint could be produced by using relatively lower heat input. In the case of $\mathrm{PET} / \mathrm{Cu}$ joint, higher heat input was necessary in welding due to specific material properties of $\mathrm{Cu}$, which has very low absorptivity of laser beam and high thermal conductivity.

An example of fracture surface image of $\mathrm{Cu}$ side after the tensile shear test for the PET/Cu joint, welded with heat input of $45.6 \mathrm{~J} / \mathrm{p}$ is shown in Fig. 2. The fracture surface observation showed the presence of PET on the metal surface. During the joining process, heat was generated at the interface and caused the PET to soften, molten and then flow onto the metal surface. Due to rapid heating and cooling of pulsed laser welding, the molten PET was solidified and tightly fused on the metal surface. Some of the remained PET could be clearly observed near the laser irradiated area and the others at the heat affected zone. Similar observations were performed for PET/A5052 and PET/SUS304 joints. Thus the schematic diagram of the joining zone of plastic and metal is illustrated in Fig. 2 (b).

Relationship between heat input and welded area is shown in Fig. 3. The welded area was measured at the interface of the joined specimen and was observed from PET side due to transparency of the plastic. Basically, the welded area for PET/SUS304 joint is larger than those for PET/Cu and PET/A5052 joints. This result indicated that most of heat energy from laser was absorbed in the case of SUS304 compared to $\mathrm{Cu}$ and A5052 specimens, which enlarged the welded area. It was also observed that the welded areas for $\mathrm{PET} / \mathrm{Cu}$ and PET/A5052 joints increased with increasing the heat input. High heat input promoted more heat generation in the surrounding region of the laser irradiated area and thus spread the joining area. On the other hand, the welded area randomly changed with the heat input for PET/SUS304 joint as shown in Fig. 3(b). This result suggests that not only heat input but also other laser welding parameters may influence the size of welded area in this joint.

\subsection{Evaluation of the joining strength}

Relationship between heat input and failure load is shown in Fig. 3. Generally, the failure load of PET/SUS304 joint was higher than those for PET/A5052 and PET/Cu joints. Besides that, the failure loads for PET/A5052 and PET/Cu joints were low when welded at the lower heat input and then increased with increasing the heat input.

High heat generation was required to obtain high failure load for PET/A5052 and PET/Cu joints, since these metallic materials have high thermal conductivity and high reflectivity of the laser. When the joints were welded with higher heat input, larger welded area was obtained, leading to the increase in the failure load. According to the joined interface observation, bubbles were formed in the PET side but size and amount of bubbles were not significantly changed with heat input variation.

In the case of PET/SUS304 joint, failure load was scattered regardless of heat input. From the observation, a small number of bubbles were formed at the interface near laser irradiation area in the PET/SUS304 joint welded with lower heat input. In addition, plenty of bubbles were observed when higher heat input was applied. The size and amount of bubbles would play important role on the joining strength. Katayama et. al. [4] have elaborated the joining mechanism, and formation of bubbles during welding could make strong bonding between a plastic and a metal. These bubbles induced high pressure into molten plastic and then these molten plastic was pushed onto the metal surface. However, large amount and coarser bubbles may reduce the joining strength if the bubbles play as defects.

Relationship between heat input and joining strength is shown in Fig. 4. As seen from the figure, PET/SUS304 joint showed greater joining strength compared to PET/A5052 and $\mathrm{PET} / \mathrm{Cu}$ joints. In the case of $\mathrm{PET} / \mathrm{Cu}$ joint, the joining strength was almost constant regardless of heat input as indicated in the figure. Meanwhile, for PET/SUS304 and PET/A5052 joints, the joining strength increased with increasing heat input. However, wide variation of joining strength was observed in PET/A5052 joint when welded at 14.4 J/p and 23.7 J/p as shown by arrows (see Fig. 4).

The cross-sectional observations of joined interface are shown in Fig. 5. From the figure, no significant molten pool could be observed in PET/Cu joint. However, in the case of PET/A5052 and PET/SUS304 joints, obvious molten pools were formed in the irradiated area. It is speculated that the molten pool was formed probably due to higher absorption of laser for PET/SUS304 joint, while low melting temperature of A5052 would induce the molten pool formation for PET/A5052 joint. It is also believed that the formation of a molten pool could make wide variation in the joining strength for PET/A5052 as mentioned above. It was also observed in all the joints that bubbles were formed inside the PET sheet.

Further consideration on molten pool depth $\left(d_{m p}\right)$ may explain characteristic of the joining strength for PET/A5052 and PET/SUS304 joints. Molten pool depths $\left(d_{m p}\right)$ for PET/A5052 and PET/SUS304 joints were measured at the cross section of the joined specimen. Relationship between $d_{m p}$ and heat input is plotted in Fig. 6. In general, a deeper molten pool was achieved with higher heat input. It is also believed that a deeper molten pool would increase the joining 


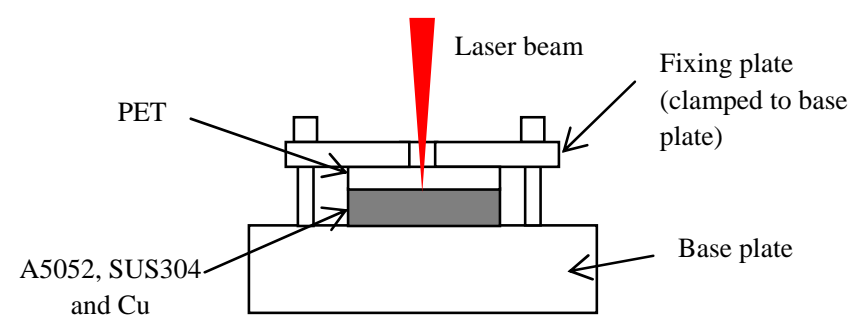

Fig. 1 Schematic diagram of the laser welding experiment.

Table 1 Physical properties of the materials used [7].

\begin{tabular}{lcccc}
\hline & PET & A5052 & SUS304 & Cu \\
\hline Density, $\mathrm{kg} / \mathrm{cm}^{3}$ & 1455 & 2680 & 8000 & 8960 \\
\hline Glass transition temperature, $\mathrm{K}$ & 353 & - & - & - \\
\hline Melting temperature, $\mathrm{K}$ & $473-528$ & $880-922$ & $1399-1454$ & 1357 \\
\hline Specific heat capacity, $\mathrm{Jkg}^{-1} \mathrm{~K}^{-1}$ & 1000 & 880 & 500 & 385 \\
\hline Thermal conductivity, $\mathrm{W} / \mathrm{m}^{-1} \mathrm{~K}^{-1}$ & 0.24 & 138 & 16.2 & 401 \\
\hline
\end{tabular}

Table 2 Welding conditions for PET and A5052, SUS304, and Cu joints.

\begin{tabular}{|c|c|c|c|c|c|c|c|c|c|c|c|}
\hline \multirow{3}{*}{$\begin{array}{l}\text { Crest } \\
\text { value } \\
\text { (V) }\end{array}$} & \multicolumn{3}{|c|}{ PET/A5052 } & \multicolumn{4}{|c|}{ PET/SUS304 } & \multicolumn{4}{|c|}{ PET/Cu } \\
\hline & \multicolumn{3}{|c|}{ Pulse duration (ms) } & \multicolumn{4}{|c|}{ Pulse duration (ms) } & \multicolumn{4}{|c|}{ Pulse duration (ms) } \\
\hline & 5 & 10 & 20 & 5 & 10 & 15 & 20 & 5 & 10 & 15 & 20 \\
\hline 100 & $\mathrm{x}$ & $\mathrm{x}$ & $\mathrm{x}$ & $\mathrm{x}$ & $\mathrm{x}$ & $\mathrm{x}$ & $\mathrm{x}$ & $\mathrm{x}$ & $\mathrm{x}$ & $\mathrm{x}$ & $\mathrm{x}$ \\
\hline 150 & $\mathrm{x}$ & 14.5 & 24.8 & $\mathrm{x}$ & $\mathrm{x}$ & $\mathrm{x}$ & $\mathrm{x}$ & $\mathrm{x}$ & $\mathrm{x}$ & $\mathrm{x}$ & $\mathrm{x}$ \\
\hline 200 & $\mathrm{x}$ & 24.5 & 41.7 & 9.7 & 17.4 & 23.6 & 28.4 & $\mathrm{x}$ & 17.3 & 23.8 & 29.4 \\
\hline 250 & 20.1 & 35.5 & 58.1 & 14.4 & 25.6 & 34.4 & 41.5 & $\mathrm{x}$ & 25.9 & 34.7 & 41.9 \\
\hline 300 & 27.2 & 46.7 & 65.5 & 19.5 & 34.0 & 44.9 & 53.9 & $\mathrm{x}$ & 34.5 & 45.6 & 55.2 \\
\hline
\end{tabular}
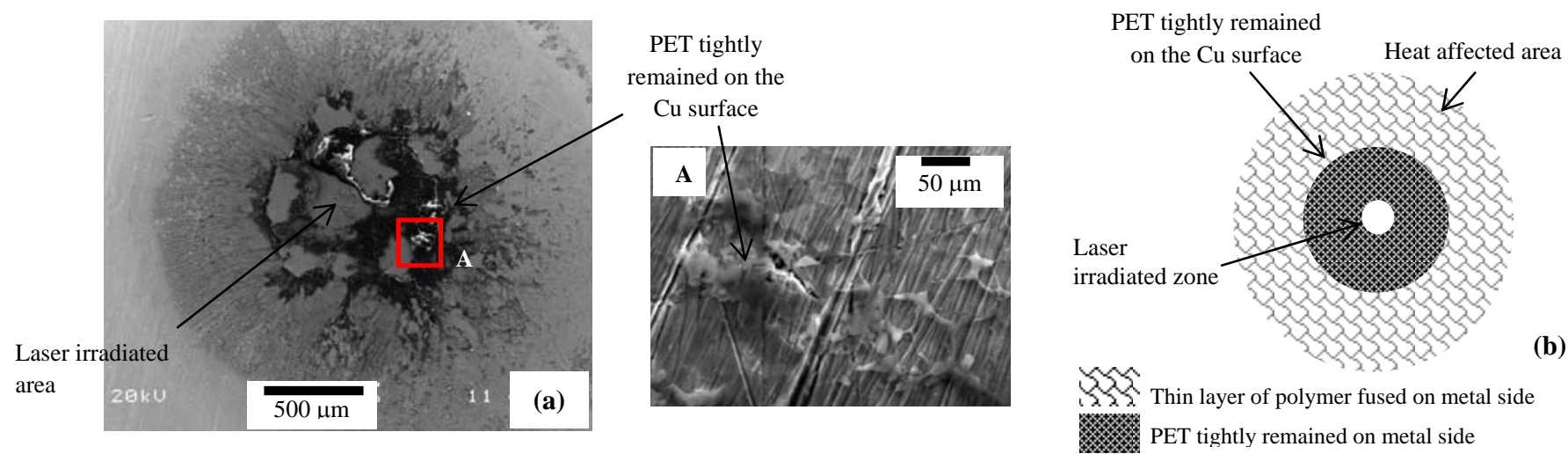

Fig. 2 (a) Overall image of fracture surface at the joint interface of $\mathrm{Cu}$ side for PET/Cu joint, and (b) Schematic diagram of fracture surface. 
strength. In the case of PET/A5052 joint, a deeper molten pool was obtained compared with that of the PET/SUS304 joint except for the highest heat input. This happens probably due to low melting temperature of A5052 in contrast to SUS304 which leads to the formation of a deeper molten pool in the heating process. As noticed from Fig. 4, the highest joining strength for PET/A5052 joint was obtained when welded at low heat input. This may result from small welded area (Fig.3) and a deep molten pool (Fig.6).

As seen from Fig. 6, a relatively shallow molten pool was obtained in the PET/SUS304 joint. However, joining strength achieved was higher than that for PET/A5052 joint. It is believed that other effect such as bubble formation would affect the joining strength of PET/SUS304 joint as discussed above. Another possible explanation would be due to occurrence of chemical reaction between plastic and metal surfaces, which could increase joining strength [4, 8]. Further investigation on the characteristics of the joined interface would give better understanding of joining mechanism. However, the formation of molten pools and bubbles was believed to contribute to the increase in the joining strength.

\subsection{Temperature distribution in the PET/ metals joining}

In the laser spot welding, rapid changes of temperature and very short duration of laser irradiation would give effects on heat distributions and characteristics of the joints. In this study, two-dimensional thermal conductive finite element analysis was carried out to study the temperature distribution during laser joining of dissimilar materials. Schematic illustration of an analyses model in the present study is shown in Fig. 7.The governing equation of transient heat conduction in two dimension cylindrical coordinates is given by [8]:

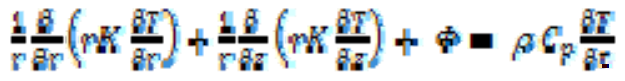

where $r$ and $z$ refer to radial and axial directions; $K, \rho$, and $C_{p}$ refer to thermal conductivity, density, and specific heat of a material, respectively; $T$ and $t$ refer to temperature and time variable, respectively; and $\Phi$ refers to internal heat generation per unit time and volume.

In laser transmission welding, the heat flux on the interface can be mathematically expressed as [9]:

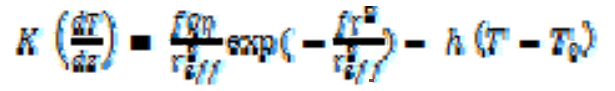

where $K$ refers to thermal conductivity; $h$ assigns as surface heat transfer coefficient, $T_{0}$ is the ambient temperature, $Q$ is the laser power, $f$ represents a power distribution factor and assumed to be 3 [9], $r_{\text {eff }}$ refers to the laser beam radius at source, and $\eta$ refers to absorption coefficient of laser power with the irradiated material and the values for A5052, SUS304 and $\mathrm{Cu}$ were taken from the references [12, 11, 2]. The first term on the right hand of Eq. (2) represents heat input from heat source which is assumed to have Gaussian distribution; the second term denotes the amount of the incident laser radiation which is transported upward.

Temperature distributions at $0.02 \mathrm{~s}$ after laser irradiation for PET/Cu, PET/A5052 and PET/SUS304 joints are schematically shown in Fig. 8 (a) - (c). As seen from the figures, the temperature scales shown at the bottom have different ranges for each analysis. The heat input value of 55 $\mathrm{J} / \mathrm{p}$ was selected for this analysis.
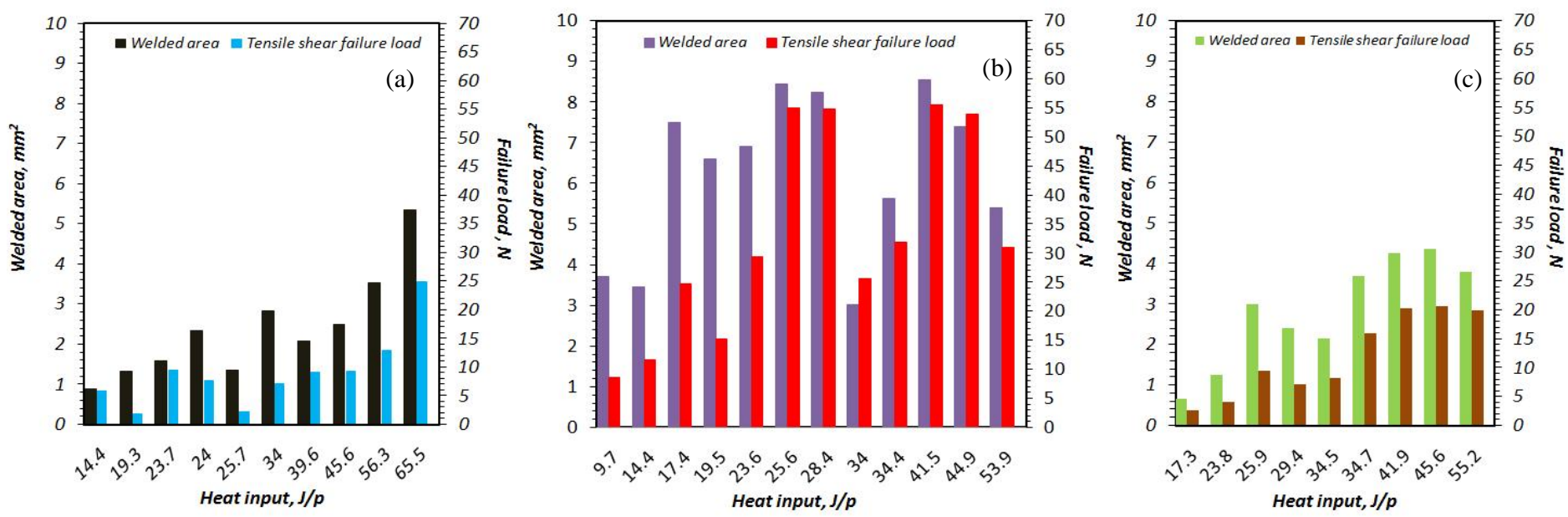

Fig. 3 Relationship between heat input and welded area or tensile shear failure load for (a) PET/A5052 joint, (b) PET/SUS304 joint, and (c) $\mathrm{PET} / \mathrm{Cu}$ joint . 
From Fig. 8(c), the PET/Cu joint shows broader temperature distribution compared to PET/A5052 and PET/SUS304 joints. Heat was rapidly dissipated throughout $\mathrm{Cu}$ substrate and the maximum predicted temperature achieved in the analysis was lower than the melting temperature of $\mathrm{Cu}$. Therefore, no molten pool would be expected to occur in $\mathrm{PET} / \mathrm{Cu}$ joint as shown in Fig. 5. Similar heat distribution pattern could be seen in the PET/A5052 joint as shown in Fig. 8 (a). However, the maximum predicted temperature was

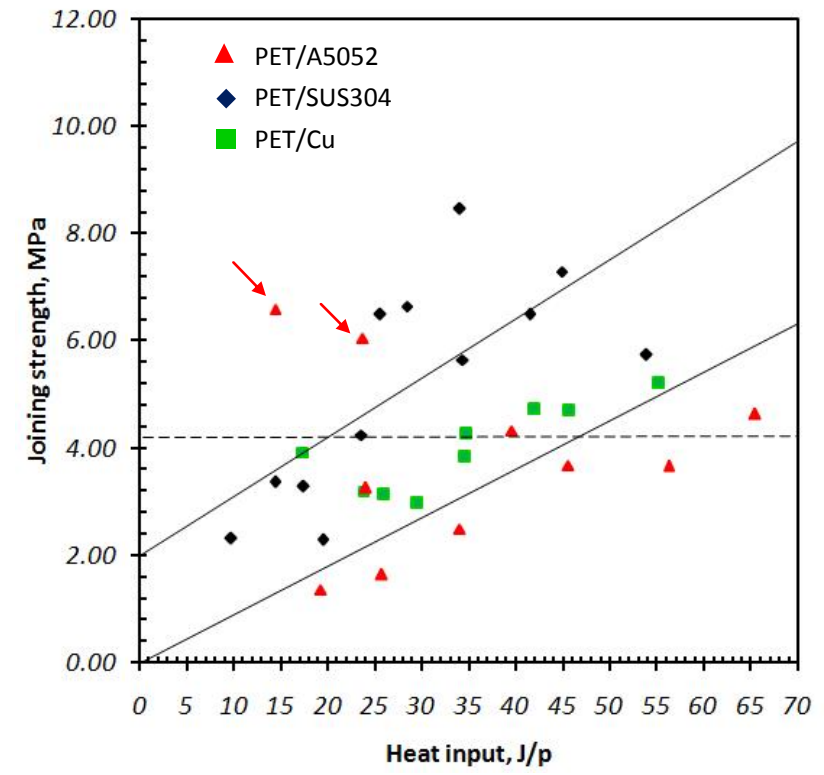

Fig. 4 Relationship between joining strength and heat input.

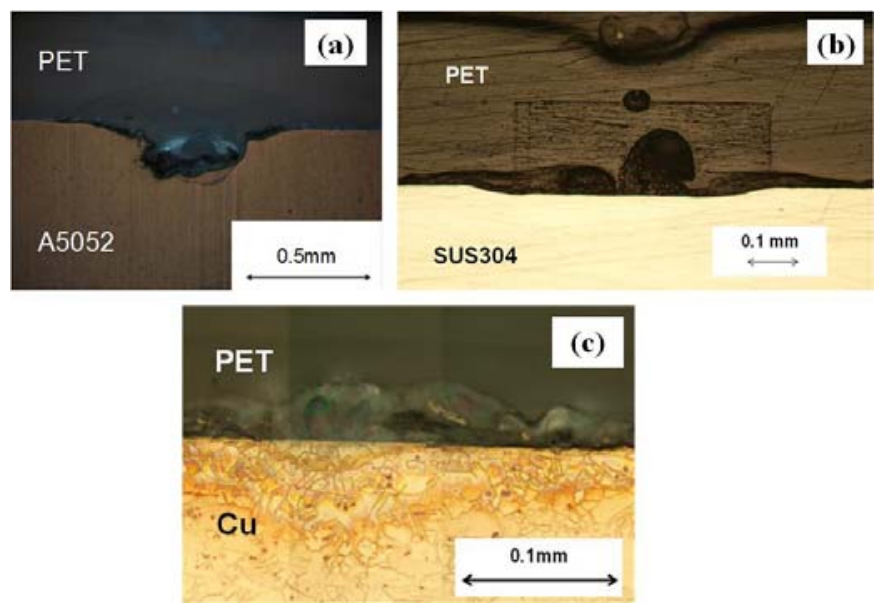

Fig. 5 Cross sectional observation at the joint interface for (a) PET/A5052 joined at $51.8 \mathrm{~J} / \mathrm{p}$, (b) PET/SUS304 joined at $41.5 \mathrm{~J} / \mathrm{p}$ (c) $\mathrm{PET} / \mathrm{Cu}$ joined at $43.5 \mathrm{~J} / \mathrm{p}$. higher than the melting temperature of A5052. Therefore the formation of molten pool would be expected to form in the joint. From the result of PET/SUS304 joint (see Fig. 8(b)), it can be seen that localized heat distribution was formed in the analysis. This indicated that most of heat was absorbed in SUS304 and high temperature was achieved [13]. The predicted temperature was much higher than melting or vaporization temperatures of PET and pores were probably formed in the PET.

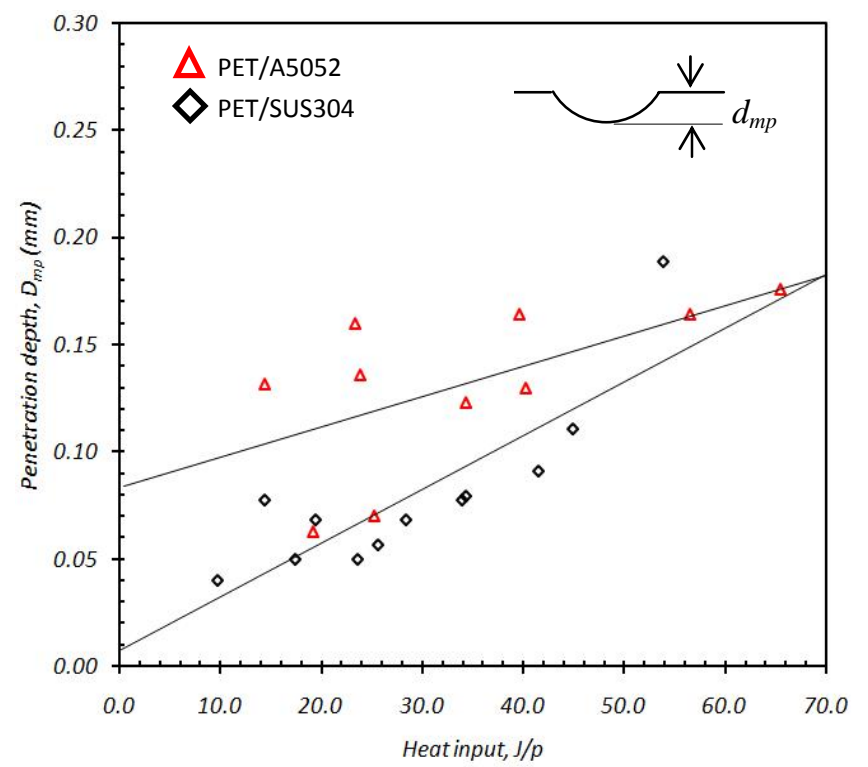

Fig. 6 Relationship between molten pool depth $\left(d_{m p}\right)$ and heat input.

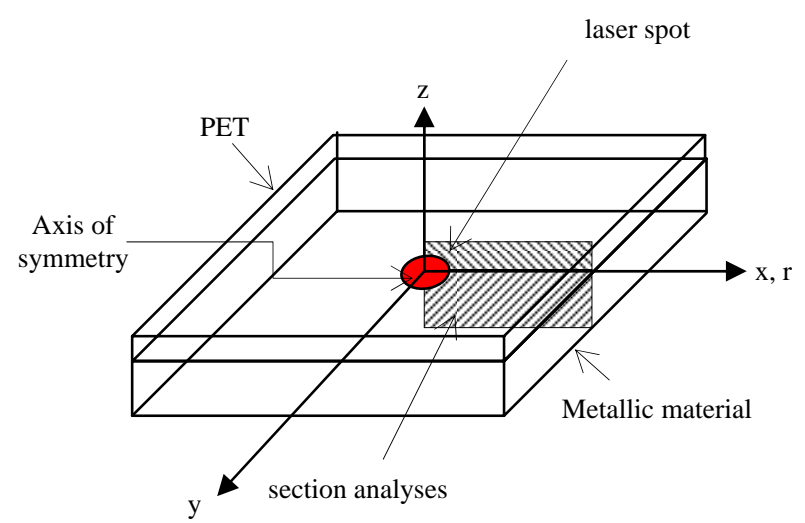

Fig. 7 Schematic illustration of an analyses model. 

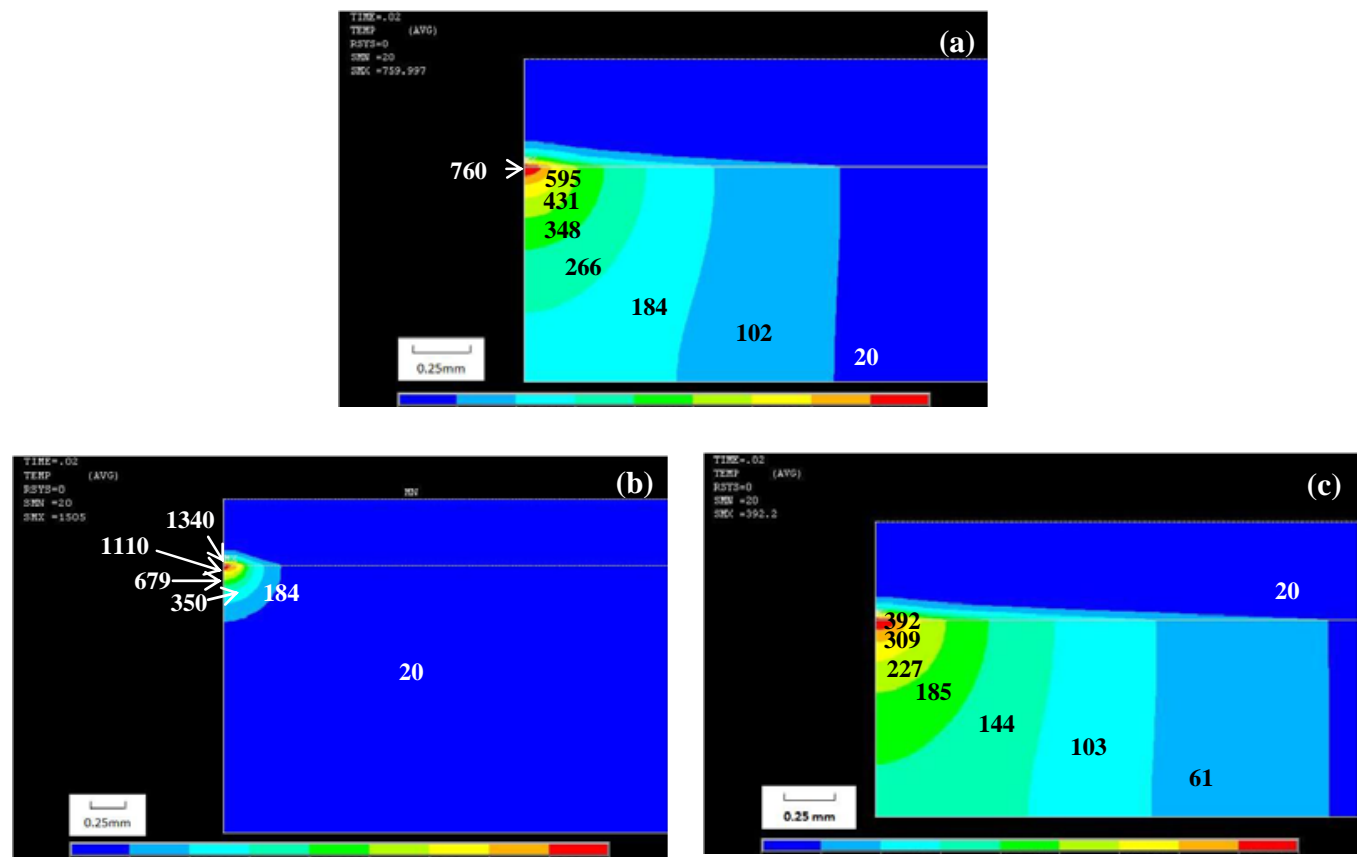

Fig. 8 Temperature distribution obtained by FEM analysis during laser joining process at 0.02s after laser radiation for (a) PET/A5052, (b) PET/SUS304 and (c) PET/Cu joint. The value of temperature is in ${ }^{\circ} \mathrm{C}$.

\section{Summary}

- PET/A5052, PET/SUS304 and PET/Cu joints could be successfully produced using Nd: YAG laser spot welding.

- Welding conditions were obtained in lower heat input for PET/SUS304 joint compared with the PET/A5052 and $\mathrm{PET} / \mathrm{Cu}$ joints. This may result from the phenomena that laser energy was well absorbed in SUS304 and simultaneously heated up the interface and produced a weld.

- In PET/Cu joint, the joining strength was almost constant regardless of heat input. In contrast, the joining strength increased with increasing heat input in the case of PET/A5052 and PET/SUS304.

- According to the cross-sectional observation of the joint, no molten pool was observed in the case of PET/Cu joint. However, obvious molten pools could be seen for the PET/A5052 and PET/SUS304 joints.

- From the result of thermal conductive analysis, heat was rapidly distributed throughout the material for the case of $\mathrm{PET} / \mathrm{Cu}$ and PET/A5052 joints. The maximum temperature obtained in the analysis indicated no occurrence of a molten pool for PET/Cu joint, which agreed with the experimental result.

\section{Acknowledgement}

Dr. Toru Sasaki in Nagaoka National College of Technology helped FEM analysis.

A part of this research work has been carried out as a research program of Grant-in-Aid for Young Scientists supported by Ministry of Education, Culture, Sports, Science and Technology (MEXT).

\section{References}

[1] Walter W. Duley : Laser Welding (A Wiley-Interscience publication 1998)

[2] J Dutta Majumdar and I Manna : Sadhana Vol. 28, Parts 3 \& 4, (2003), p 495-562

[3] Edmund Haberstroh, Wolf-Martin Hoffmann, Reinhart Poprawe, Fahri Sari : Microsyst Technol (2006) 12: 632-639

[4] Seiji Katayama and Yousuke Kawahito: Scripta Materialia Volume 59, Issue 12, (2008), p 1247-1250

[5] Yukio Miyashita, Masaharu Takahashi, Masashi Takemi, Kosei Oyama, Yoshiharu Mutoh and Hironori Tanaka: Journal of Solid Mechanics and Materials Engineering, Vol. 2, No. 2, (2009), p409-415

[6] Y. Farazila, Y. Miyashita, Y. Mutoh, and Y. Otsuka: Proc. of $47^{\text {th }}$ JSME General Congress Hokuriku Shinetsu Branch, (2010), p 285-286

[7] http://www.matweb.com/ (access at June 2, 2010).

[8] Grigor L. Geoorgiev, Taslema Sultana, Ronald J. Baird, Gregory Auner, Golam Newaz, Rahul Patwa, Hans Herfurth : Applied Surface Science 254, (2008) , p 7173 - 7177

[9] S. Bag, A. Trivedi, A. De: International Journal of Thermal Sciences 48, (2009), p 1923-1931

[10] Z.A. Taha, G.G. Roy, K.I. Hajim and I. Manna: Scripta Materialia 60, (2009), p 663-666

[11] P.W. Fuerschbach and G.R. Eisler: Science and Technology of Welding and Joining, Vol.7 No. 4, (2002), p $241-246$

[12] Pavel Kotalik and Thomas Boeck: Proc. Appl. Math. Mech. 8, (2008), p 10623-10624

[13] X. He, T. DebRoy, P.W. Fuerschbach: Journal of Applied Physics, Vol. 94, No. 10, (2003), p 6949 - 6958.

(Received: June 07, 2010, Accepted: February 21, 2011) 